\title{
Solar Thermal Power Sector
}

\author{
S P VISWANATHAN* \\ Empereal-KGDS Renewable Energy Pvt. Ltd., Coimbatore 641 035, India
}

(Received on 30 March 2014; Accepted on 14 August 2015)

\begin{abstract}
Solar power will play a significant role in India's future energy mix. In addition to be able to provide process heat, concentrated solar power (CSP) plays a unique role in India's energy production because of its potential to use hybrid technologies with biomass or fossil fuels. Thermal energy storage is another aspect of solar thermal technology which helps provide dispatchable and base-load power. The low pressure steam available at the outlet of the power turbine can be utilized for other processes such as air-conditioning and thermal desalination. At high temperatures that can be brought about by concentrating solar thermal technology, hydrogen gas can be produced which serves as a clean fuel. Despite many advantages, much more needs to be done to scale-up CSP sustainably. Innovation and indigenization can address some of the barriers that pose challenges for the development of CSP market in India.
\end{abstract}

Keywords: Solar Thermal Power; CSP Performance; CSP Technology Improvements and Challenges; CSP Market in India; Solar Thermal Desalination

\section{Introduction}

Concentrated solar thermal power (CSP) technologies have the potential to meet various forms of our energy needs on par with conventional fossil fuel and nuclear power technologies. By suitably selecting the concentration level, we can meet various process parameters required to carry out simple room heating/ cooling, power generation, and high temperature material and chemical processing in an environmentfriendly and sustainable manner. Owing to its wide range of applications, CSP technology offers a useful solution to global warming and steadily increasing demand for fossil fuels. Unlike solar photovoltaic (PV) technologies, CSP technology has an inherent capacity to store energy in the form of heat energy (International Energy Agency, 2010). CSP has the ability to provide transportable fuel and reliable electricity generation that can be dispatched to the grid even round the clock to meet the demand.
Generation of electricity using various CSP technologies employing conventional power cycle has significant potential in the global energy mix. Owing to the common power cycle, CSP technology can be easily integrated with conventional fossil fuel or biomass based power plants. At present, based on the type of concentration optics and temperature requirements, the four main CSP technologies shown in Fig. 1, are widely employed to generate power and process heat. The possibility of using CSP technologies to produce concentrating solar fuels (CSF) is an important area for further research and development. Solar-generated hydrogen can help to decarbonize the transport and other sectors by mixing hydrogen with natural gas, and by producing cleaner liquid fuels (Chu Yinghao, 2011). Collectively, these characteristics make CSP a promising technology to meet our future energy needs in a greener and cleaner manner.

*Author for Correspondence: E-mail: spv@kgisl.com 


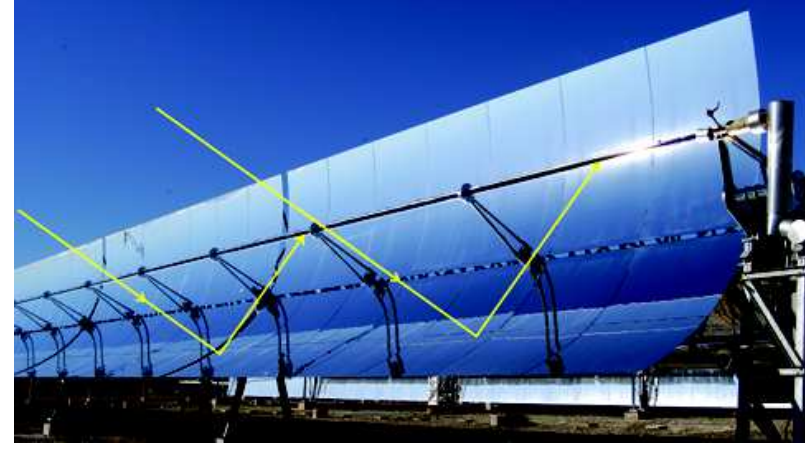

A : Parabolic trough, DLR, AG

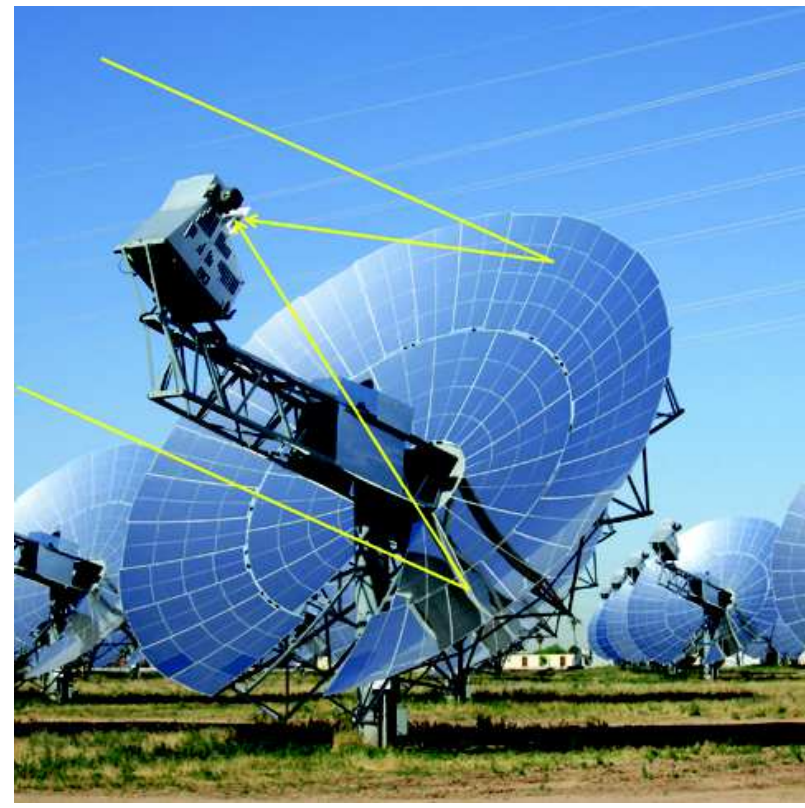

C: Dish Stirling system. Maricopa Solar Plant, SunCatcher

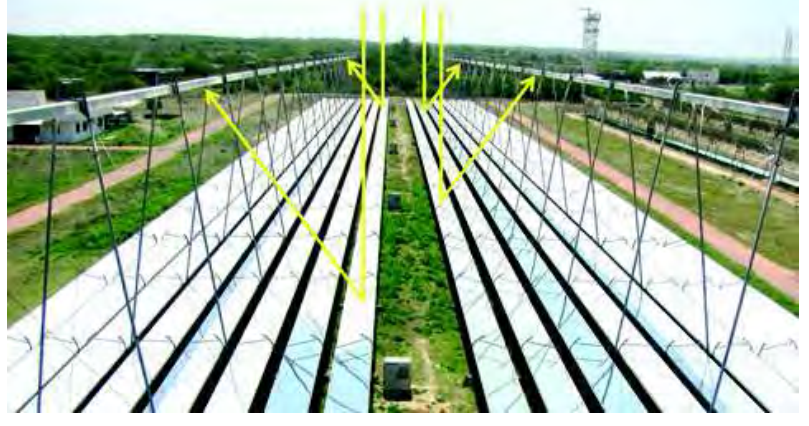

B : Linear Fresnel, Empereal-KGDS Renewable Energy Pvt. Ltd.

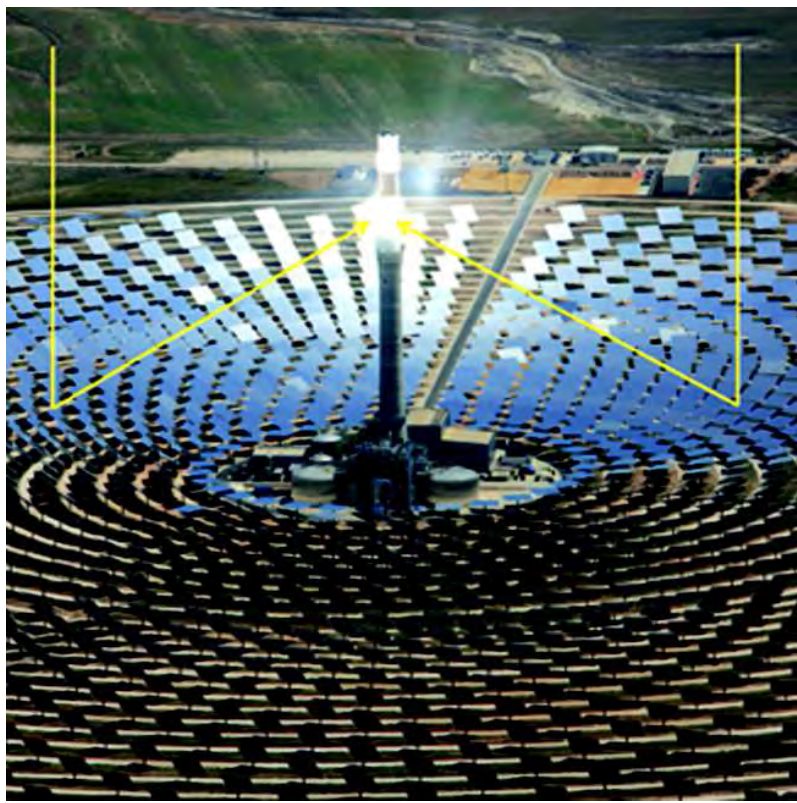

D: Solar tower, Gemasolar, Spain

Fig. 1: Four main CSP technologies

\section{Global Scenario of Solar Thermal Power Sector}

At the end of 2010, there was 1,318 $\mathrm{MW}_{\mathrm{e}}$ (MW electrical) of cumulative installed CSP capacity worldwide, with nearly 20 GWe of capacity in the pipeline (National Renewable Energy Laboratory, 2011). In 2010, Spain was the world leader in CSP installations, with $450 \mathrm{MW}_{\mathrm{e}}$ of added capacity and $55.4 \%$ of cumulative installed capacity worldwide. Meanwhile, USA added $78 \mathrm{MW}_{\mathrm{e}}$ of CSP capacity, for a total of $38.5 \%$ of cumulative installed CSP capacity worldwide. Iran (5.0\%), Israel $(0.5 \%)$, Australia (0.2\%), and Germany $(0.1 \%)$ have all recently entered the CSP market. Projects now in development or under construction and in planning in more than a dozen countries (including China, India, Morocco, Spain and USA) are expected to total several GWe. Parabolic troughs account for the largest share of the current CSP market, but competing technologies are emerging. Some plants now incorporate thermal storage.

Spain, North Africa, Australia, and the Middle East are promising markets for CSP on account of the regions' high levels of insolation and land availability for solar deployment. The world insolation map in Fig. 2 depicts the most ideal areas for CSP development. 


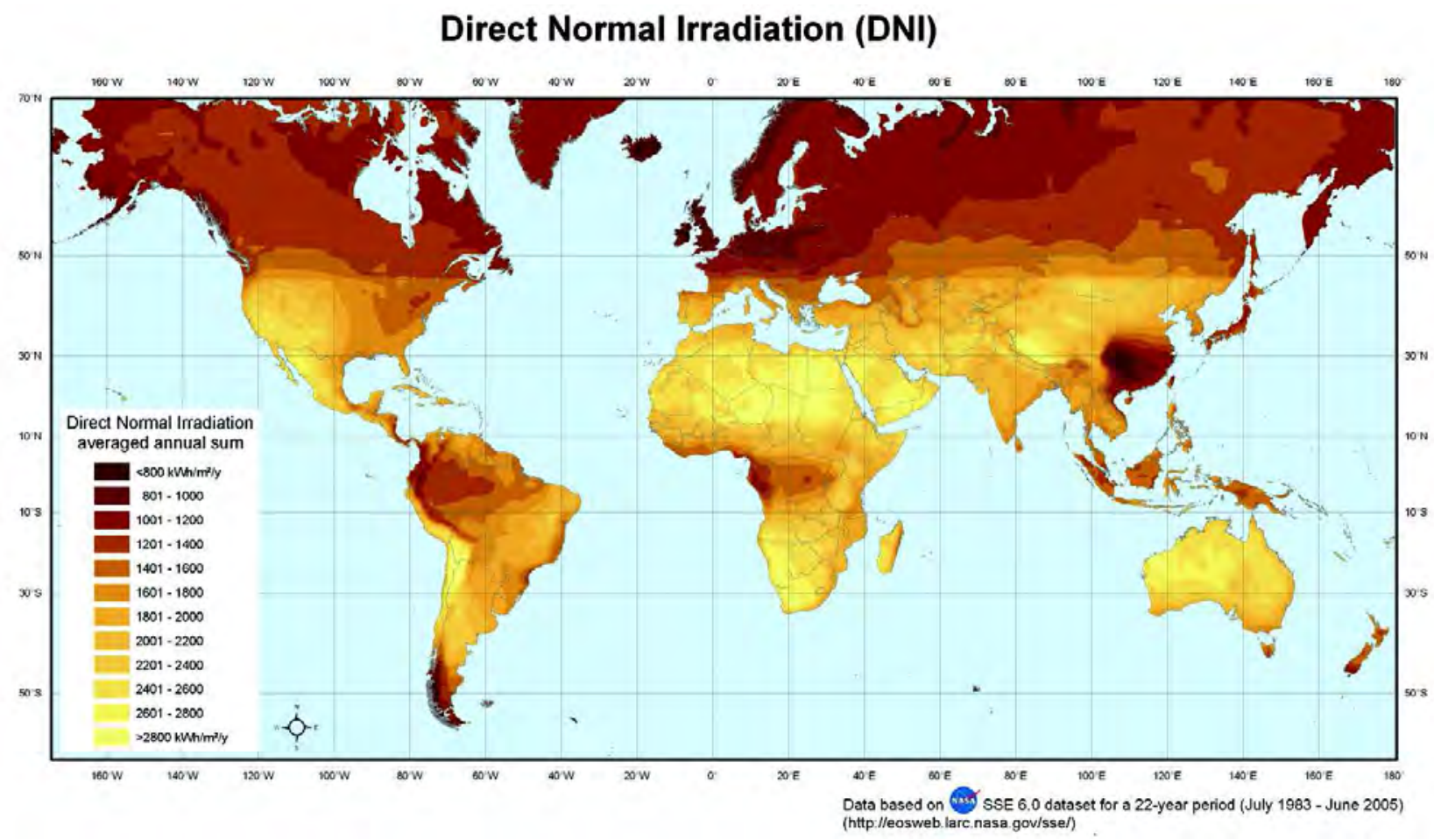

Fig. 2: World insolation map. Source: DLR (2008)

The first commercial CSP plant in Spain, the 11 MW tower system known as PS10 (Protermo Solar, 2010), was completed in 2006. With a high capacity factor, PS10 can generate $24 \mathrm{GWh} /$ year, which is enough to supply about 5,500 households with electricity. Andasol 1, which came online in November 2008, has a maximum capacity of $50 \mathrm{MW}$ and was the first trough system in Europe. Andasol 1 was also the first commercial CSP plant with an energy-storage capability designed specifically for electricity generation after sunset. This added feature enables the plant to provide electricity for approximately 7.5 $\mathrm{h}$ after sunset. Two additional plants, the Puertollano Plant and PS20, totalling $70 \mathrm{MW}$, were set up in Spain in 2009. In 2010, Spain added nine more CSP plants totalling $450 \mathrm{MW}$.

Just to the south of Spain, North Africa also has tremendous potential for CSP growth. Fig. 2 reveals the favourable solar irradiation in North African countries.

By late 2010, Morocco constructed a hybrid system with $20 \mathrm{MW}$ of CSP that will be combined with a natural gas plant for a total generation of 472
$\mathrm{MW}_{\mathrm{e}}$. Similar plants were under construction in Algeria and Egypt. This type of design, known as an integrated solar combined cycle (ISCC), has gained some traction in these regions. The Tunisian Solar Plan aims to install a total capacity of $4.7 \mathrm{GW}_{\mathrm{e}}$ of renewables by 2030 , which will represent $40 \%$ of the total installed capacity, with a budget of 2.3 billion euros.

Interest in CSP had also been growing in the Middle East for reasons similar to those in Africa such as high solar irradiation, available land and growing demand for clean energy. Abu Dhabi has launched a large CSP plant (SHAMS 1) of capacity $100 \mathrm{MW}_{\mathrm{e}}$ on March 2013. Shams 1 uses parabolic trough technology. Unlike photovoltaic solar panels, CSP concentrates heat from direct sunlight onto oil-filled pipes, produces steam, and drives a turbine and generates electricity. The solar project reportedly uses a natural gas-fired superheater to boost steam temperatures (from $380^{\circ} \mathrm{C}-540^{\circ} \mathrm{C}$ ) before it enters the turbine to dramatically increase the cycle's efficiency. It also includes a dry-cooling system that significantly reduces water consumption which is a critical advantage in the arid desert of western Abu Dhabi. 


\section{Indian Scenario of Concentrated Solar Thermal Power Sector}

India is endowed with abundant solar energy, which is capable of producing 5,000 trillion kilowatt-hours of clean thermal energy per year. India is blessed with around 300 sunny days in a year and solar insolation of 4-7 $\mathrm{kWh}$ per $\mathrm{m}^{2}$ per day. If this energy is harnessed efficiently, it can easily reduce our energy deficit scenario and that too with no carbon dioxide emission.

Many states in India have already recognized and identified the potential of solar energy and others are lined up to meet their growing energy needs with clean and everlasting solar energy. In the future, solar energy will have a huge role to play in meeting India's energy demand. Fig. 3 shows the direct normal irradiance in India.

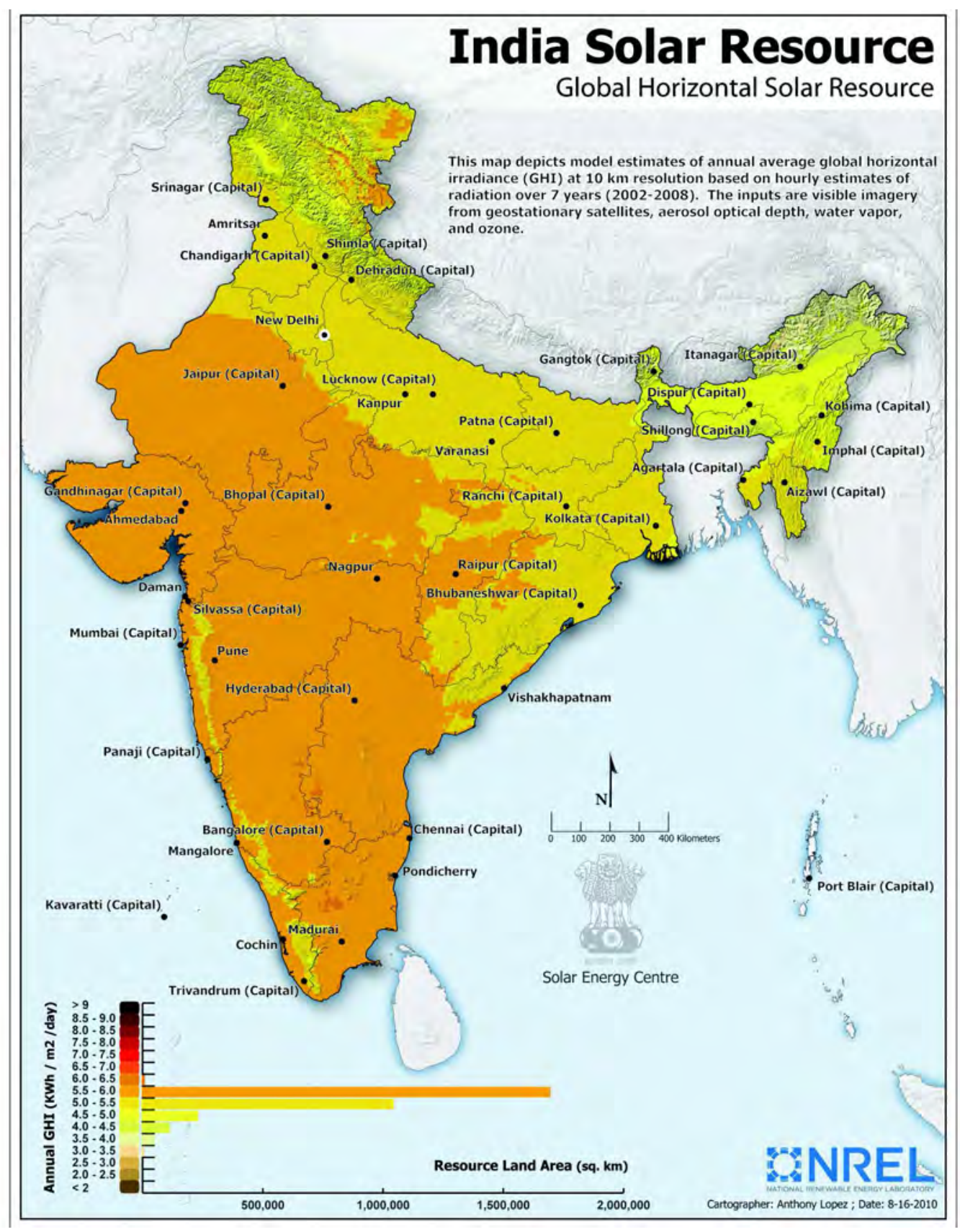

Fig. 3: Direct normal irradiance in India. Source: MNRE, Annual DNI (2010) 
The main enabler for photovoltaic and CSP projects is the Jawaharlal Nehru National Solar Mission (JNNSM). The Solar Mission was launched by the Prime Minister, Manmohan Singh in January 2010. It focuses on a target of $20 \mathrm{GW}_{\mathrm{e}}$ of solar capacity by 2022 . In the first phase, $1 \mathrm{GW}_{\mathrm{e}}$ of grid-connected solar was targeted for 2013 with an approximate 50:50 split between CSP and photovoltaic (PV) technologies. From 17.8 megawatts (MW) in early 2010, cumulative installed capacity reached 506.9 MW by the end of March 2012 out of which only 2.5 MW of CSP was in operation. However, there are seven projects of 470 MW aggregate capacity scheduled to be completed by May 2013 under the first phase of the JNNSM (report commissioned by the Australian government and prepared by IT Power, 2011).

India's first 2.5 MWe CSP plant (Fig. 4A) was commissioned in April 2011 at Bikaner, Rajasthan.

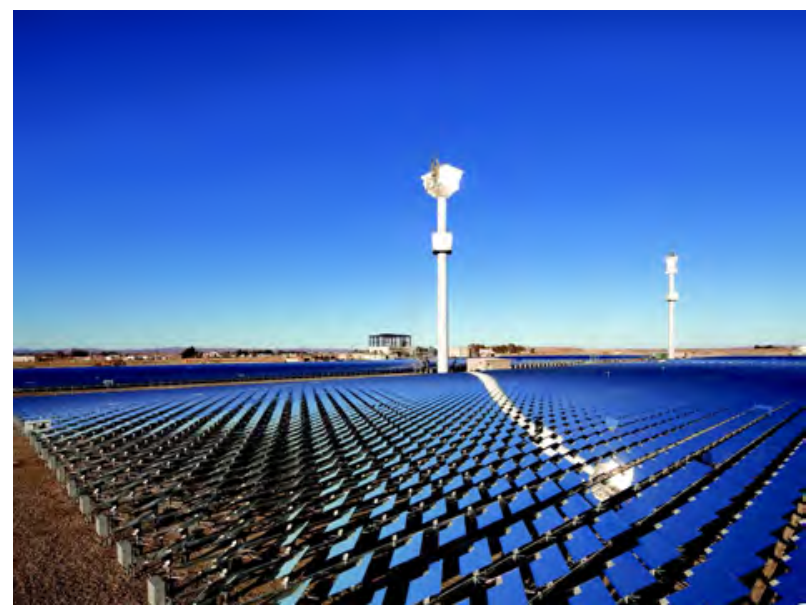

A: 2.5 MW $\mathrm{MW}_{\mathrm{e}}$ Solar Tower, Rajasthan, (ACME, Rajasthan)

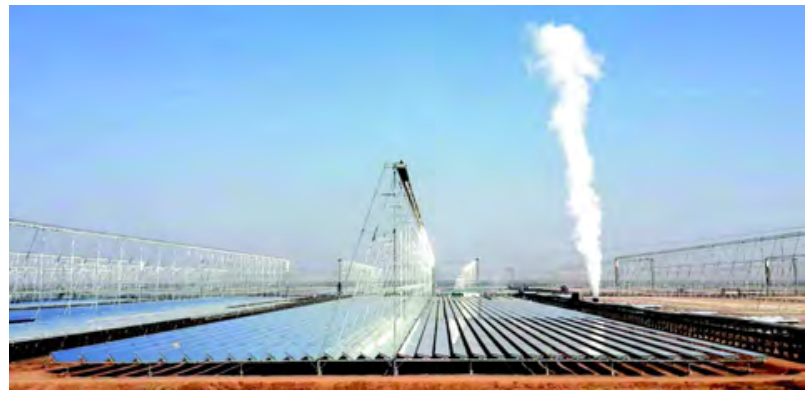

B: 125 MW solar thermal plant of Reliance (Areva, Dhursar)

Fig. 4: CSP plants in India based on tower and LFR
The plant, developed by ACME Group, employs eSolar power tower technology. During 2012-14, a $125 \mathrm{MW}$ CSP was built by Areva for Reliance Power Ltd. in Dhursar, Rajasthan employing the linear Fresnel technology (Fig. 4B).

A total of $125 \mathrm{MW}_{\mathrm{e}}$ LFR-based solar thermal power plants and $350 \mathrm{MW}_{\mathrm{e}}$ of parabolic trough power plants are in various stages of development in Rajasthan and Gujarat.

\section{Various $R \& D$ Activities}

Two Types of Solar Steam Generating Systems : One of the systems based on fixed receiver E-W automatically tracked concentrating technology (Scheffler Dish) and the other on fully tracked receiver using dish technology (Arun Dish), were developed under MNRE research projects. These systems are used for cooking, process heat, laundry, food and other processing industries. Fig. 5 A\&B shows the pictures of Arun Dish and Scheffler Dish, respectively. Also a $1 \mathrm{MW}_{\mathrm{e}}$ Scheffler Dish power plant with $16 \mathrm{~h}$ of thermal storage is under construction at Mt. Abu (MNRE, Solar steam generating systems, 2011).

The $1 \mathrm{MW}$ power generation facility is "an experimental project" being built collaboratively by the Solar Energy Centre (SEC) and the Indian Institute of Technology Bombay. The project is being implemented by IIT Bombay and a consortium of partners consisting of Empereal-KGDS Renewable Energy Pvt. Ltd., Coimbatore, Abengoa, Tata Power, Tata Consulting Engineers, Larsen \& Toubro, Clique, KIE Solatherm. The linear Fresnel system of Empereal-KGDS produces dry saturated steam at 45 bar and $257^{\circ} \mathrm{C}$ with a $2 \mathrm{MW}$ thermal power capacity. It is superheated to $370^{\circ} \mathrm{C}$ in a heat exchanger by the $390^{\circ} \mathrm{C}$ thermic fluid of the Abengoa parabolic trough system with $3 \mathrm{MW}$ thermal power. The two superheated steam streams are combined to produce $5 \mathrm{MW}$ thermal power at $370^{\circ} \mathrm{C}$. This produces $1 \mathrm{MW}_{\mathrm{e}}$ electrical power from the steam turbine.

With funding from Department of Science and Technology (DST), Government of India, EmperealKGDS Renewable Energy Pvt. Ltd. Coimbatore and National Institute of Ocean Technology (NIOT), 


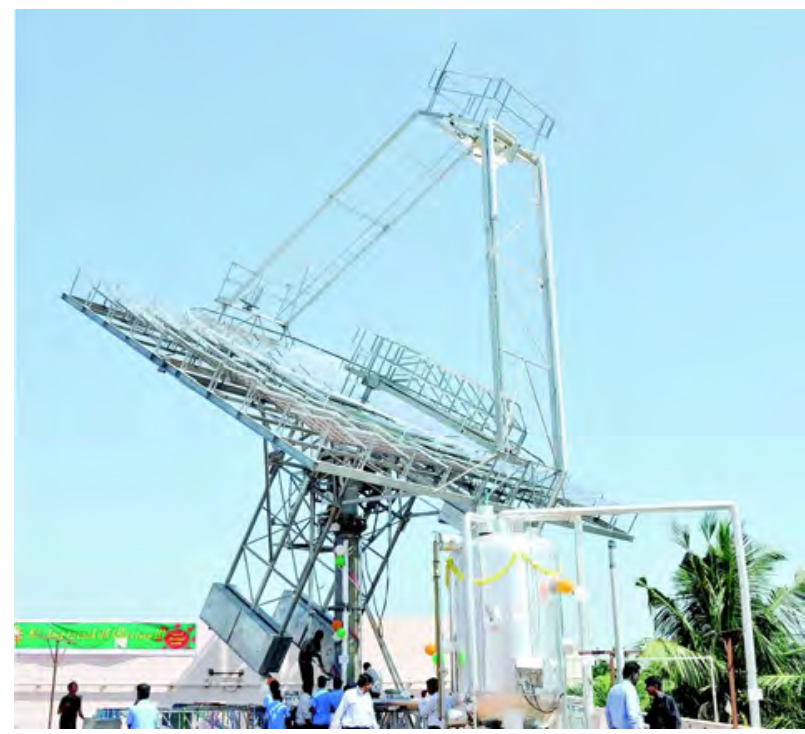

A

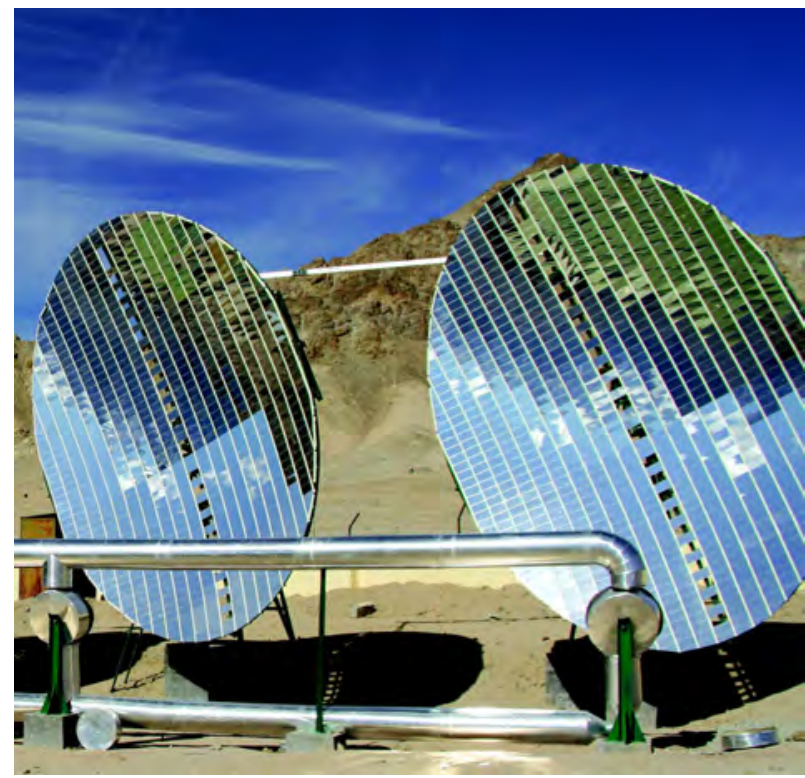

B

Fig. 5: A: Arun Dish at Ramakrishna Mission's Students' Home, Chennai and B: Scheffler Dish at JNV School, Leh-Ladakh

Ministry of Earth Sciences, in Chennai collaboratively developed a Solar-Biomass Multi-Effect Distillation System at Narippaiyur village in Ramanathapuram district of Tamil Nadu. The plant produces $6000 \mathrm{~kg} / \mathrm{h}$ distilled water of less than $5 \mathrm{ppm}$ total dissolved solids from the 32,000 ppm sea water drawn from the Bay of Bengal.

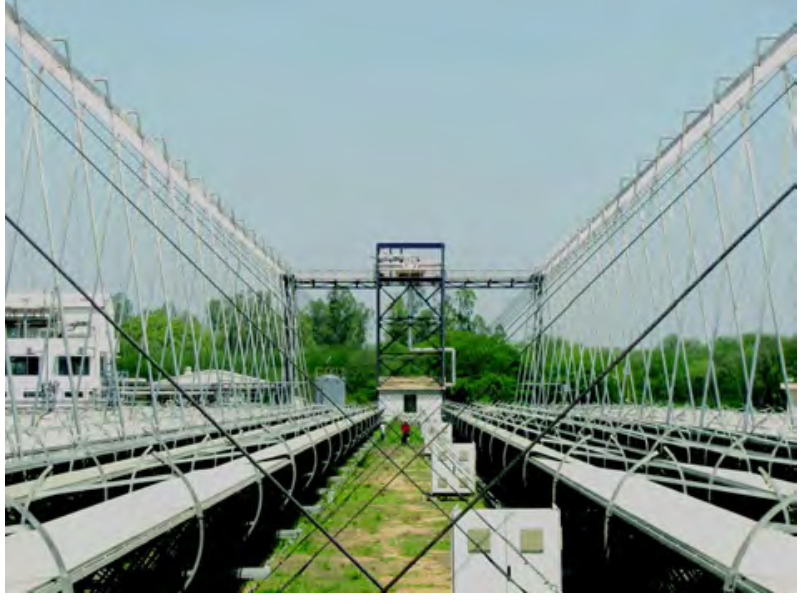

A

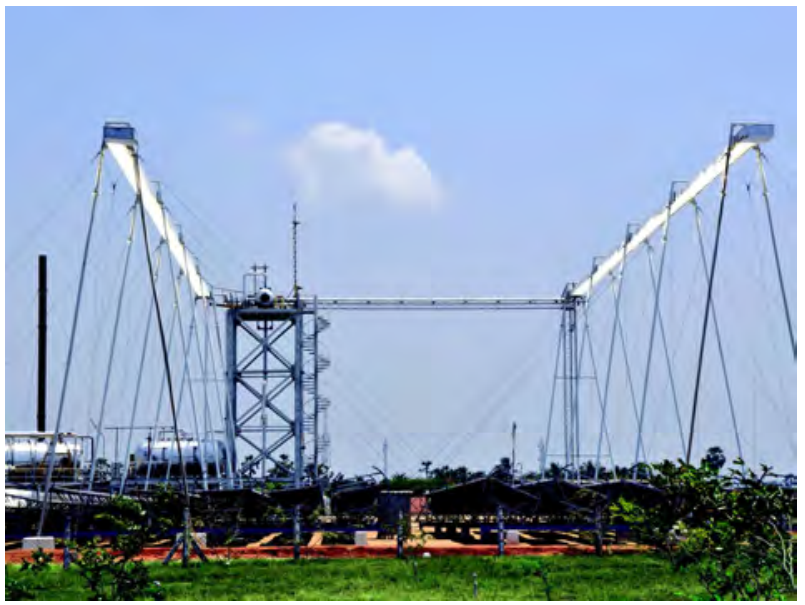

B

Fig. 6: A: LFR solar energy collector at Solar Energy Centre, Gwalpahari and B: Solar-biomass hybrid thermal desalination system at Ramanatha-puram district, Tamil Nadu

\section{Performance Model of CSP Technologies}

This chapter discusses the mathematical model that characterizes the performance of line focus and point focus CSP technologies. CSP technologies employ mirrors to concentrate sunlight onto a receiver where the energy is absorbed by heat transfer fluids (HTF) such as water, oil, molten salt and air. Suitable working fluid is employed to drive conventional power cycles such as Rankine cycle, Brayton cycle and Sterling engine to generate power. The three major components of CSP are solar collector/reflector field, receiver and the power block. 
Here, general mathematical model of solar energy collector is discussed (Sukhatme and Nayak, 2008).

The efficiency of the system is calculated by

$$
\eta_{\mathrm{th}}=Q_{\mathrm{out}} /\left(I \times A_{C}\right),
$$

where $Q_{\text {out }}$ is thermal power output of the system $(\mathrm{kW}) ; I$ is solar direct normal irradiance $\left(\mathrm{kW} / \mathrm{m}^{2}\right) ; A_{\mathrm{C}}$ is solar collector area $\left(\mathrm{m}^{2}\right)$; and $Q_{\text {out }}$ is calculated from the total energy absorbed by the heat transfer fluid.

$$
Q_{\text {out }}=\dot{m} \times C_{\mathrm{p}} \times\left(T_{\text {out }}-T_{\text {in }}\right),
$$

where $\dot{m}$ is mass flow rate of the heat transfer fluid $(\mathrm{kg} / \mathrm{s}) ; C_{\mathrm{p}}$ is specific heat capacity of heat transfer fluid $(\mathrm{kJ} /(\mathrm{kg} \mathrm{K}))$ and $T_{\text {out }}$ and $T_{\text {in }}$ are outlet and inlet temperatures of heat transfer fluid (K).

However, if a phase change takes place, the thermal power output is the product of the mass flow rate and the enthalpy increases from inlet to outlet.

Theoretically, $Q_{\text {out }}$ can also be calculated using the following formula.

$$
Q_{\text {out }}=\left(I \times A_{C} \times \eta_{\text {opt }}\right)-Q_{\text {loss }}
$$

The optical performance of the line focus is limited by

- Shading losses due to the adjacent reflectors shadowing the incident rays

- Cosine losses due to non-alignment of the reflector with respect to the direct beam radiation

- Intercept losses due to the spillage of reflected rays onto the receiver tube

- Line end losses when the reflection misses the absorber in the longitudinal direction due to the fact that the sun is not exactly overhead at solar noon. This effect is particularly visible in the winter months.

- Optical errors due to material, construction or tracking

- Reflectivity of the mirror, transmissivity of the glass envelope and absorptivity of the receiver tube.
- Heat losses from the receiver which depend upon the heat transfer coefficient of the fluid, emissivity of the absorber tube, geometry of the receiver, convective medium outside the receiver tubes and ambient conditions.

$\eta_{\text {opt }}=$ Cosine factor $\mathrm{x}$ Shading factor $\mathrm{x}$ Intercept factor $\mathrm{x}$ Reflectivity $\mathrm{x}$ Transmissivity $\mathrm{x}$ Absorptivity

The heat loss of the receiver is the heat loss from the outside surface of the absorber tube which is the sum of convective and radiative losses from the absorber tube to the surroundings.

$$
\begin{aligned}
Q_{\mathrm{g}}= & \left(h_{\mathrm{g}} \times A_{\mathrm{g}} \times\left(T_{\mathrm{g}}-T_{\mathrm{a}}\right)\right) \\
& +\left(F_{\text {rad }} \times \sigma \times \varepsilon_{\mathrm{g}} \times A_{\mathrm{g}} \times\left(T_{\mathrm{g}}^{4}-T_{\mathrm{s}}^{4}\right)\right),
\end{aligned}
$$

where $h_{\mathrm{g}}$ is convective heat loss coefficient at outside of the glass surface $\left(\mathrm{W} / \mathrm{m}^{2} . \mathrm{K}\right) ; F_{\text {rad }}$ is radiation view factor; $\sigma$ is Stefan-Boltzmann Constant; $\varepsilon_{\mathrm{g}}$ is emissivity of glass; $T_{\mathrm{a}}$ is ambient temperature $(\mathrm{K}) ; T_{\mathrm{g}}$ is glass temperature $(\mathrm{K}) ; T_{\mathrm{s}}$ is sky temperature $(\mathrm{K})$ and $A_{\mathrm{g}}$ is surface area of glass $\left(\mathrm{m}^{2}\right)$.

The performance of a CSP plant is measured by its annual solar-to-electric conversion efficiency. This metric includes all of the energy losses that affect the annual electricity produced by the plant, including optical, thermal, and electrical parasitic losses, as well as forced and planned outages for maintenance. Capacity factor is defined as the ratio of actual annual generation to the amount of generation had the plant operated at its name plate capacity for the entire year. Capacity factors vary greatly between different locations, technologies, and plant configurations. CSP plants with thermal energy storage (TES) are likely to be more cost-effective in the future than plants without TES, because, while the addition of low-cost TES does increase capital costs, it has the potential to reduce the levelized cost of energy (LCOE).

\section{Current Research Areas for Technology Improvements in CSP}

Development of More Advanced Reflectors, Receivers and Heat Transfer Fluids

Advanced Reflectors and Tracking System : To increase performance and reduce costs of CSP plants, 
all components of CSP plants have to be improved, particularly the solar field elements (International Renewable Energy Agency, 2013). Effective but costly back-silvered, thick-glass curved mirrors could be replaced with troughs based on less expensive technologies such as acrylic substrates coated with silver, flexible aluminium sheets covered with silver or aluminium, or aluminium sheets glued to a glass fibre substrate.

Historically, Flabeg has been a primary manufacturer of bent glass reflectors, providing products with $95 \%$ or better reflectivity. PPG Industries and Rioglass also manufacture glass reflectors, and aim to lower capital costs of glass and increase durability. Emerging companies such as Reflec Tech, and $3 \mathrm{M}$ offer polymer films with comparable reflectivity. They are up to $60 \%$ lighter, and said to be more durable than glass. Alloy mirrors are also contending with glass reflectors. Patriot Solar Group introduced a clear, acrylic plastic surface with an aluminium or zinc backing, while Alanod-Solar manufactures nano-composite-coated, anodized alloy Miro-Sun mirrors. Glass manufacturers such as Rioglass suggest that polymer films suit only smaller installations with less serious durability requirements.

Development of self-cleaning coatings for reflector surface will greatly reduce the water consumption, one of the key problems in the arid regions where most of CSP plants are being built. Innovative compact reflector array configurations are required to improve land usage and other relevant material consumption. Wider troughs, with apertures close to $7 \mathrm{~m}$ (versus 5 to $6 \mathrm{~m}$ currently) and smaller capacity tower are under development, and offer the potential for incremental cost reductions. Development of new mirror supports and low power drives are very much needed to achieve overall cost reduction and auxiliary power consumption (International Renewable Energy Agency, 2012).

Tracking system scheme for small heliostat fields must be further improved. Current tracking system is based on the use of one drive per heliostat. However, small heliostat developers are developing a system based on a common row tracking with microrobotic drives that couple at each heliostat individually.
Such a system can bring about a total tracking system cost reduction of 40\% (Kearney and ESTELA, 2010).

\section{Receivers and Coating}

The current glass-to-metal seal of the evacuated tubes that collect solar energy could be replaced with a mechanical seal, if it proved capable of preserving the necessary vacuum for 20 years or more. Further improvements in the absorptance coating of the tubes, and reduction in emissivity at the operating temperatures could increase efficiency significantly.

The research team at University of California at San Diego is working to develop new hightemperature spectrally selective coatings (SSC) for receiver surfaces (National Renewable Energy Laboratory, 2012). The coating employs surfaceprotected semiconductor nano-particles to drastically reduce heat loss and allow for higher temperature receiver operation. The optical properties of the SSC directly determine the efficiency and maximum attainable temperature of solar receivers, which in turn influence the power-conversion efficiency and overall system cost. The proposed SSCs are aimed at achieving solar absorptance of $>94 \%$ and infrared emittance of $<7 \%$ at $750^{\circ} \mathrm{C}$. These achievements can enable thermal receiver efficiencies of $>90 \%$ and operation temperatures of heat-transfer fluids above $650^{\circ} \mathrm{C}$.

Improvement in the power tower receivers with high temperature heat transfer fluid will raise efficiency up to $28 \%$. High-temperature tower concepts also include atmospheric air as the heat transfer fluid (tested in Germany with the Jülich Solar Tower Project) with solid material storage. Solar-toelectricity efficiencies of up to about $25 \%$ can be delivered by such tower receivers.

\section{Heat Transfer Fluid}

Replacement of the costly heat transfer fluid currently used by trough plants should be considered because synthetic oil limits the steam temperature to about $380^{\circ} \mathrm{C}$ due to degradation at higher temperatures. Direct steam generation (DSG) in the collector fields would allow high working temperatures and reduced investment costs, as no heat transfer fluid and heat 
exchangers would be necessary. DSG needs to be demonstrated in troughs on a large scale, but more research is needed to design specific options for storage with DSG, ensure the separation of water and steam, and handle the circulation of high-temperature, high-pressure working fluids, which is a challenge with mobile receivers.

Pressurized gas receiver is currently under testing at the Plataforma Solar de Almeria, Spain. Additional research is needed to improve heat transfers in the receiver tubes, and to ensure control of the solar field, which is more complex than the standard design. Molten salts used in the collector field simplify storage, as the heat transfer fluid becomes the storage medium. Salt mixtures usually solidify below $200^{\circ} \mathrm{C}$, however. Hence, further research is necessary to reduce the pumping and heating expenses incurred to protect the field against freezing.

New liquids, in particular nanofluids are being investigated. Nano particles enhance the heat capacity of current HTF by introducing nanoscale phase change particles. Supercritical carbon dioxide $\left(\mathrm{S}-\mathrm{CO}_{2}\right)$ operated in a closed-loop recompression Brayton cycle offers the potential of equivalent or higher cycle efficiency versus supercritical or superheated steam cycles at temperatures relevant for CSP applications.

Very High Temperature Solar Energy Collector for Material Processing, Solar Fuel Production and Advanced Power Cycles

In EU SOLASYS project, solar steam reforming of a methane-containing gas has been successfully demonstrated in a solar reformer at the Weizmann Institute of Science (WIS) in Rehovot, Israel. The necessary solar reformer was developed at DLR, then built and tested on a 400 kilowatt (thermal) scale. The novel pressure reformer is heated with concentrated solar radiation, which enters the reformer through a domed quartz glass window. In the reformer, the radiation then strikes a ceramic structure, which is highly porous and thus gaspermeable, and which is catalytically active. The radiation is absorbed in the bulk of this structure and heats it to about $800^{\circ} \mathrm{C}$ or more. The methanecontaining gas flowing through heats up and reacts on the surface of the catalyst to form synthesis gas (DLR, 2005).

Concentrating solar thermal technologies also allow the production of hydrogen $\left(\mathrm{H}_{2}\right)$, which forms the basis of fuels, or carriers, that can help store solar energy and distribute it to industry, households and transportation, substituting fossil-based fuels with lowemission solar energy. Solar towers and large dishes are capable of delivering the required amount of heat at appropriate temperatures.

The HYDROSOL-II project has developed a thermochemical technology that produces hydrogen solely from solar energy and water, up to the pilot plant scale. Aerosol \& Particle Technology Laboratory (APTL, Greece), DLR (Germany, concentrating solar technologies), Johnson Matthey (U.K., automotive catalysis), Stobbe Tech Ceramics (Denmark, ceramic manufacturing), and the Centro de Investigationes Energéticas, Medioambientales Tecnológicas (CIEMAT, Spain, solar tower facilities) are involved in HYDROSOL-II (Trommer et al., 2005).

In order to produce solar gas by solar steam reforming, CSIRO has installed a $250 \mathrm{~kW}$ natural gas reforming pilot plant. CSIRO is also developing catalysts for carbon dioxide reforming (CDRM, known as dry reforming) and mixed reforming (SRM+CDRM). Research on similar projects such as SOLASYS and SOLREF is being carried out by DLR, Germany. Further research is being conducted in Japan and Israel.

Solar furnaces receive solar radiation by one or more heliostats such as solar towers. However, instead of a tower with central receiver, a parabolic mirror is used as a secondary optical component to concentrate the sunlight up to 20,000 times. The parabolic mirror may be facetted because single mirrors are restricted in their size. The largest solar furnaces in Odeillo, France, and Parkent, Uzbekistan, have thermal power of $1 \mathrm{MW}$ and size equivalent to a 12-storey building. 


\section{Storage Technology and Hybrid Plant Configuration}

Incorporating thermal energy storage enables CSP plants to provide power generation over a longer period (after sunset, for instance) or to shift power delivery to another time period. Therefore, it provides plant operators more flexibility, allowing them to accurately match electricity supply with demand as well as support grid reliability. However, thermal storage for 3-6 h will increase the capital cost due to storage equipment. Therefore, different power tariffs should be mandated for peak hour supply. Development of low-cost high-efficiency thermal storage technology is also essential to achieve cost reduction (NREL, 2003).

Selection of materials for storage (storage medium) plays an important role in the design of thermal storage system. Various materials have been addressed in the literature for both sensible and latent heat storage systems based on their thermo-physical properties (Bauer et al., 2010; Hoshi et al., 2005). CSP plant with more than $16 \mathrm{~h}$ of thermal storage using two-tank molten salt storage technology is operational in Spain (ANDASOL II). Thermoclinebased storage technology having a single tank filled with low cost sand, rock and mineral oil is being developed (Pacheco et al., 2001).

A few studies (Bayón et al., 2010; Laing et al., 2011 and Bahl, C. et al., 2009) report different thermal storage systems for direct steam generation. Bahl et al. (2009) proposes a three-part storage system for a direct steam generation device using concrete and PCM. The concrete storage modules are used for preheating and superheating the steam and the PCM storage module is used to evaporate the heat transfer fluid. Integration of thermal storage system with power plant is considered favourable for the future market potential of such power plants (Feldhoff et al., 2012). Steam accumulators integrated with suitable latent heat storage material is a promising option for most of the process heat applications.

Intermittency of solar energy and non-availability during night time makes hybridization an important aspect of CSP plants to achieve continuous operation of the plant. So, suitable hybridization schemes such as solar-biomass and solar-fossil fuel must be developed and demonstrated (MNRE, 2012) for reliability, cost-effectiveness and durability.

\section{Challenges for CSP Technology in India}

\section{CSP Technology and System Components}

Import of key CSP technology and system components such as mirrors, absorber tubes, and other special balance of plant items lead to high cost of the CSP plants. Indigenous technology development and production of these components in the future will help deploy more CSP plants (National Solar Mission Interim Report, September 2012).

\section{Solar Resource Data}

India's solar programme hinges on the reliability of the solar resource data. In recent years, private developers have put in place ground measurements, predominantly in Gujarat and Rajasthan. The government has additionally tendered 50 stations to be distributed all over India, which will "significantly improve resource data" in the coming years. Solar thermal technology is successful in areas with high solar radiation.

\section{Water Scarcity}

Similar to other conventional power plants, concentrated solar power plants require water for condensing the steam used to power the electric turbine. In India, sun-rich areas such as Rajasthan or Gujarat (or cold desert of Ladakh) are already short of water resources. Air-cooled condensers can reduce the water requirement significantly, but the capital cost of air-cooling, and associated performance loss are significant. Non-availability of water can be solved by cogeneration of power and water in coastal areas. Solar thermal power plants can be coupled with desalination plants where sea water can be desalinated through multiple-effect distillation. Coastal areas of Gujarat, Tamil Nadu, etc., receive very good solar radiation, so implementation of solar desalination plants in such areas is a viable solution to power and water scarcities (DST Annual Report, 2013). 


\section{Financial and Policy Issues}

Relatively high capital cost of Indian CSP plants due to lack of Indian supply chain must be properly addressed (National Solar Mission Interim Report, April 2012). Financial institutions and policy makers need to understand the technology, resource availability and the need for CSP technology emphasizing the ability of CSP technology to meet our future baseload requirements and production of transportable fuel. CSP is in a state of infancy but has vast potential to meet our future energy needs.

\section{Concluding Remarks}

CSP has excellent application in hot desert environments with high solar radiation and high

\section{References}

Bahl C, Doerte Laing, Matthias Hempel and Andreas Stückle (2009) Concrete Thermal Energy Storage for Solar Thermal Power Plants and Industrial Process Heat, German Aerospace Center (DLR), Institute of Technical Thermodynamics, Germany

Bauer T, Doerte Laing and Rainer Tamme (2010) Overview of PCMs for concentrated solar power in the temperature range 200 to $350^{\circ} \mathrm{C} \mathrm{Adv} \mathrm{Sci} \mathrm{Technol} 74272-277$

Bayón R, Esther Rojasa, Loreto Valenzuela, Eduardo Zarza and Javier León (2010) Analysis and experimental behavior of a $100 \mathrm{kWth}$ latent heat storage system for direct steam generation in solar thermal power plants Appl Therm Eng 30 2643-2651

Chu Yinghao (2011) Review and comparison of different solar energy technologies. Research Associate, Global Energy Network Institute (GENI) charlie0586@address.com Under the supervision of and edited by Peter Meisen President, Global Energy Network Institute (GENI) www.geni.orgpeter@geni.org (619) 595-0139

DLR (2005) Solar Fuel Production http://www.dlr.de/en/ Portaldata/1/Resources/kommunikation/publikationen/ 109_nachrichten/dlr-nari109_en_68-71.pdf

DLR (2008) Direct Normal Irradiation http://www.dlr.de/tt/ Portaldata/41/Resources/dokumente/institut/system/ projects/reaccess/ssedni60.jpg

DST Annual Report (2013) http://www.dst.gov.in/about_us/ar1213/annual-report-2012-13.pdf ambient temperatures. In order to realize the full potential of CSP, the industry should develop various building blocks with which the CSP technology can be assembled. For example, reflectors with low cost and high durability should be developed. Once largescale production takes place, CSP capital cost will decrease promoting more demand for the CSP plants. Government policies should help develop large-scale production facilities. Solar thermal storage will make the plant dispatchable, and hybridization with other technologies will help to produce power after sunset. High temperature CSP plants can help produce renewable fuels. Funding for basic and applied research will promote vigorous development of the CSP technology which will result in good returns in the long run.

Feldhoff J F, Kai Schmitz, Markus Eck, Lars SchnatbaumLaumann, Doerte Laing, Francisco Ortiz-Vives and Jan Schulte-Fischedick (2012) Comparative system analysis of direct steam generation and synthetic oil parabolic trough power plants with integrated thermal storage Solar Energy 86 520-530

Hoshi, A., David R. Mills, Antoine Bittar and Takeo S Saitoh (2005) Screening of high melting point phase change materials (PCM) in solar thermal concentrating technology based on CLFR Solar Energy 79 332-339

International Energy Agency (IEA) (2010) Technology Roadmap - Concentrating Solar Power, https://www.iea.org/media/ freepublications/technologyroadmaps/csp_roadmap 2010.pdf

International Renewable Energy Agency (IRENA) (2012) Renewable energy technologies: cost analysis series Volume 1 Power Sector Issue 2/5 pp 24

International Renewable Energy Agency (IRENA) (2013) Concentrating solar power- Technology IEA-ETSAP and IRENA@ Technology Brief E10 - January 2013 www.etsap.org - www.irena.org

Kearney AT and ESTELA (2010) Solar Thermal Electricity 2025, ESTELA, Brussels.http://www.estelasolar.eu/index.php? $\mathrm{id}=22$

Laing D, Carsten Bahl, Thomas Bauer, Dorothea Lehmann and Wolf-Dieter Steinmann (2011) Thermal energy storage for direct steam generation Solar Energy 85 627-633

MNRE (2012) http://mnre.gov.in/file-manager/UserFiles/draftjnnsmpd-2.pdf 
MNRE (2010) Annual DNI; http://mnre.gov.in/sec/DNI_ Annual.jpg

MNRE (2011) Solar steam generating systems: http://mnre.gov.in/ file-manager/UserFiles/Brief_Solar_Steam_ generating Systems.pdf

National Renewable Energy Laboratory (NREL) (2003) Assessment of Parabolic Trough and Power Tower Solar Technology Cost and Performance ForecastsSubcontractor Report, Contract No. DE-AC36-99-GO10337

National Renewable Energy Laboratory (NREL) (2011) 2010 Solar Energy Market Report

National Renewable Energy Laboratory (NREL) (2012) www.nrel.gov/docs/fy12osti/55465.pdf

National Solar Mission Interim Report (April 2012) Laying the Foundation for a Bright Future

National Solar Mission Interim Report (September 2012) Concentrated Solar Power: Heating up India's Solar Thermal Market under the National Solar Mission
Pacheco J E, Steven K Showalter and William J Kolb (2001) Development of a molten-salt thermocline thermal storage system for parabolic trough plants, Proceedings of Solar Forum 2001 Solar Energy: The Power to Choose, 21-25 April 2001, Washington, DC

Report commissioned by Australian Government and prepared by IT Power (2011) Concentrating Solar Power in India

Sukhatme SP and Nayak J K (2008) Solar Energy; Principle of Thermal Collection and Storage, Third Edition, Tata McGraw-Hill Education Pvt. Ltd., 2008 ISBN 10: 0070260648/ISBN 13: 9780070260641

Trommer D, Noembrini F, Fasciana M, Rodriguez D, Morales A, Romeroc M and Steinfeld A (2005) Hydrogen production by steam-gasification of petroleum coke using concentrated solar power-I. Thermodynamic and kinetic analyses Int $J$ Hydrogen Energy (Impact Factor: 2.93). 05/2005; 30 605618. DOI: 10.1016/j.ijhydene.2004.06.002 605-618. 